\title{
HACIA UNA TEORÍA SIMBIÓTICA DE LA LITERATURA
}

\author{
TOWARDS A SYMBIOTIC LITERARY THEORY
}

Laro DEL RÍO CASTAÑEDA

Universidad de Oviedo

riolaro@uniovi.es

La literatura tiene que ver con todo. No puede separarse de la política, de la religión y de la moral. Es la expresión de las opiniones de los hombres sobre todas las cosas. Como todo en la naturaleza, es a la vez efecto y causa. Describirla como un fenómeno aislado es no describirla.

Benjamin Constant (apud Todorov, 2009: 62)

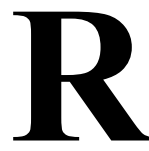

ebasar fronteras. Teoría de la Literatura e interdisciplinariedad

Decía Althusser (1970: 44-45) que todo trabajo teórico es al mismo tiempo una crítica que rectifica y una producción novedosa: resulta imposible no tomar unos referentes terminológicos, metodológicos e ideológicos previos y construir con ellos un texto al menos mínimamente distinto al original. Más allá de prejuicios concretos y premisas aceptadas sin pensar, aquí estamos hablando de una gigantesca masa de información cultural sobre la que nos elevamos, de la que tomamos las palabras y las ideas. Son las otras teorías que nosotros asumimos y utilizamos, con las que nos identificamos, a través de las que nos expresamos y contra las que respondemos, hasta el punto de valernos de ellas para descontextualizarlas, recontextualizarlas e incluso tergiversarlas (De Certeau, 1996; Derrida, 2010).

Sin necesidad de llegar a los extremos deconstruccionistas, queda claro que la labor teórica implica por definición la reformulación del discurso, la actualización del léxico, las estructuras, las contradicciones, los vacíos, los pensamientos y los relatos anteriores. Ante esta situación, una tendencia reconocible en la historia de los estudios literarios ha sido la creación teórica a partir de la negación de un dogma ya establecido — con lo que la nueva teoría «no llega a salir del marco de la concepción criticada» (Todorov, 1978: 12)— . Otra fórmula habitual ha sido la de matizar, aplicar o profundizar en una noción perteneciente a un determinado ámbito de estudio. En nuestro caso, hasta que la Teoría Literaria no hubo logrado un reconocimiento académico suficiente, fueron habituales los intentos de dignificación (hasta cierto punto cientifistas y positivistas) que limitaban su enfoque a una 
parcela muy concreta del saber, distinta de aquellas de las que se encargaban otras ramas del conocimiento. De nuevo, en esta segunda opción es difícil hallar una salida del marco teórico original: la institucionalización de las diversas perspectivas de los estudios literarios obliga a detallar un espacio propio, dibujar fronteras con otras disciplinas, marcar las diferencias que nos especifican.

Cabe señalar, en este sentido, que la Teoría de la Literatura y la Literatura Comparada siempre han incluido en su corpus y en su bibliografía académica realidades a priori más propias de otros campos del saber, cuyos estudios, por cierto, no siempre han recibido la atención pertinente por parte de los teóricos. La «dieta unilateral» era, para Wittgenstein (2008: 491, §593) la principal de las enfermedades filosóficas, y todavía hoy no hemos sido capaces de superar del todo la convencionalidad de ciertas divisiones institucionales, más históricas, políticas o administrativas que gnoseológicas. Ya Fokkema (1989), a principios de la década de los ochenta, recomendaba la cooperación de los diversos estudiosos de la literatura, teóricos y comparatistas junto con expertos de otras áreas de investigación, en pos de la acumulación y la exploración de un único objeto común. Todo aquel que se obligue a hacer arqueología en el devenir histórico de su ámbito de estudios podrá darse cuenta de la relatividad, flexibilidad e imprecisión de sus límites; su estatuto como discurso resulta frágil y disperso (Foucault, 1970). «Las disciplinas académicas tienen historias, pero no esencias», ha sintetizado Haun Saussy (2006 apud Sánchez-Mesa Martínez, 2015: 80).

Por todo ello, la intención de este monográfico va un paso más allá de las dos posibilidades arriba expuestas: propone dar voz a autores que entienden que los estudios literarios han de criticar y producir no solo en función de la rectificación de una teoría existente ni de la profundización monotemática y ciega a otros descubrimientos. Esto no significa que estas mecánicas de trabajo no merezcan respeto; sobra decir que una gran parte del conocimiento - de las ciencias humanas y de las naturaleselaborado hasta la actualidad responde a aquellos esquemas. Siempre será necesario romper tópicos, desencajar presunciones acríticas y problematizar prejuicios; siempre resultará de utilidad comprobar los confines más profundos y las conclusiones últimas de cada corriente académica particular. Pero buscamos otra cosa: el diálogo entre ramas diversas, ese «trabajo interdisciplinar que resulta muy común en la ciencia actual y que, a nuestro entender, define el estatuto epistemológico de la teoría de la literatura» (Núñez Ramos, 2017: 222). A lo que hay que puntualizar, sin embargo, que no se pretende una suma de todos los saberes y todas las tendencias, ya que resultaría ilógica, desproporcionada e insatisfactoria. Ya avisaba Walter Watson, uno de los defensores del pluralismo más destacados del siglo XX, de que «nuestras perspectivas disciplinares no restringen — por mor de sus limitaciones - el grado de verdad que podemos alcanzar, sino que, más bien, es a través de estas limitaciones como es posible alcanzar una verdad apropiada a cada perspectiva» (2008: 75). Nos interesan los nudos, la confluencia de ideas y datos, la combinación de dos o más facetas —íntegras, completas en sí, diría Watson-que puedan aliarse y complementarse a la hora de arrojar luz sobre un objeto tan polifacético como la literatura.

Los artículos que siguen a estas líneas, por tanto, participan de alguna manera de este combinado teórico; y son parte, en esencia, de un conjunto de eventos con el mismo interés en lo interdisciplinar: 
el III Congreso Internacional de la Asociación Española de Teoría de la Literatura celebrado en Oviedo en enero de 2019, titulado «Transversales: teoría y literatura en relación con otros ámbitos del saber y de la experiencia», y la pronta publicación en diversas revistas académicas de monográficos con temáticas semejantes. Con el fin de ser coherentes con cierta relajación institucional, se han respetado, dentro de unos límites rigurosos indispensables, la diversidad de formato. Aprovechamos por último este final de párrafo para agradecer al equipo de Tropelías todo su trabajo y la oportunidad que nos brinda con la difusión de las ideas y teorías de estos trece autores.

\section{Qué viene a continuación: princesas, autobiografías, booktubers y sonetos}

En «Ficción literaria: De la intertextualidad ilimitada a la proteicidad textual», Miguel Amores Fúster entiende la ficción como un rasgo propio del ser humano que aparece en la gran mayoría de los campos del saber, pero que revela una naturaleza especial en el caso de la literatura al carecer esta de un soporte fundamental en la realidad empírica. Tras recordar algunas concepciones de la ficción, desde Aristóteles a Doležel, Genette y Walsh, así como las dificultades que a lo largo de la historia de los estudios literarios ha presentado como objeto de conocimiento independiente, Amores Fúster subraya la importancia de una de sus características fundamentales: la proteicidad. La ficción literaria carece de restricciones de forma o contenido, a diferencia de cualquier texto que esté atado a lo factual, por lo que también es capaz de elegir sus propias condiciones de sentido. Esto significa, por ende, que en lo que concierne a la intertextualidad, un texto ficcional puede establecer cualquier relación con cualquier otro texto posible. Hasta el punto de asimilarse completamente a otro tipo de discurso o género y hacer suyos sus modos de generación de sentido.

En «La Filosofía y la Psicología en la Hermenéutica literaria de la Ilustración», María José Rodríguez Sánchez de León vuelve la vista al siglo XVIII, un momento en el que la Hermenéutica sin contar con una corriente estrictamente literaria establecida de manera sólida- discute la importancia de lo histórico, universal, objetivable y de lo psicológico, particular, subjetivo a la hora de interpretar un texto. Su relevancia reside en la presencia cada vez más habitual de discursos críticos con la intención autorial y favorables a admitir la variabilidad de lo emotivo, lo perceptual y lo vivencial. Ante esta revalorización de la recepción supuestamente espontánea e instintiva, se pone en duda el papel (distanciador) del estudio y la crítica racionales de la literatura, que alejan la lectura del placer catártico y directo. El prerromanticismo ilustrado se plantea así reflexiones sobre el objeto estético que van más allá de la intelectualización; es la Psicología inundando los terrenos de la Filosofía y la Hermenéutica.

En «De las lecturas de época: intentio auctoris versus intentio operis. Sobre un soneto de Francisco de Aldana», Rosa Eugenia Donces Montel indaga acerca de la misreading, la sobreinterpretación y la interpretación manquée. Para desglosar las posibles naturalezas de este fenómeno, opta por el comentario breve de algunos casos muy distintos entre sí, con obras pertenecientes a varias etapas históricas, desde el Medievo hasta el siglo XX, y con malinterpretaciones 
que afectan a diversos niveles de la obra literaria, como el léxico, el narratológico o el pragmático. De ello se desprende gradualmente una reflexión teórica que dialoga con obras de la hermenéutica clásica, obteniendo especial provecho de las palabras de Umberto Eco y E. D. Hirsch: el valor de la intentio auctoris - parece suscribir Donces Montel— no debería olvidarse en favor de la intentio operis. La última parte del artículo analiza con mayor profundidad la recepción académica del soneto de Francisco de Aldana «Otro aquí no se ve que, frente a frente», recogiendo las interpretaciones de su último verso — que, podría decirse, dota al poema del sentido final—, posicionándose con respecto a ellas y, por último, revalorizando el paradojismo y la antítesis como mensajes propios de la obra literaria.

En «¿Es algo la novela? Pasos preliminares para una nueva definición», Miguel Alonso Lavandero se opone a la tradición académica que ha estudiado el género novela. Su crítica no se funda tanto en desacuerdos parciales o matizables, sino que ataca radicalmente la generalidad de un término que acoge obras dispares y sin rasgos en común. La manera de leer, los efectos, placeres y reflexiones que se obtienen de la recepción de obras que habitualmente denominamos novelas son demasiado variados. Wittgenstein y los parecidos de familia son el punto de partida para negar la posibilidad de una definición universal de novela. Asumido esto, Alonso Lavandero decide estudiar las obras asociadas a este género en subgrupos; y concreta su propuesta con una clase en particular creada a partir de una definición de Gonzalo Sobejano. Dirimir los distintos elementos que la componen permitirá dibujar un espacio en el que quepan unas obras (Los premios de Cortázar) y otras (La novela luminosa de Levrero, El congreso de literatura de Aira, el Quijote de Cervantes) queden fuera. Las implicaciones teóricas del artículo, por tanto, sirven para repensar ciertas categorías asentadas en los estudios literarios y sacar a la luz los criterios apriorísticos en que se sustentan. Tener conciencia de la convencionalidad relativamente arbitraria de esta terminología favorece una investigación más profunda y honesta.

En «Indicios novelescos: Una lectura de Fortunata y Jacinta de Galdós», Blanca Fernández García se adentra en la literatura realista del siglo XIX sirviéndose del «paradigma indiciario», modelo epistemológico definido por Carlo Ginzburg en 1979. Focaliza, así, en las cosas aparentemente intrascendentes $-\mathrm{y}$ por lo general involuntarias por parte del autor- pero de las que se infiere una ausencia: huellas, síntomas, impresiones externas. El tipo de desciframiento de estos signos permite clasificar el género novelístico en diversos subgéneros, dependiendo de si estos son pruebas (policial), presagios (de adivinación o histórica) o detalles (realista o naturalista). En el enfoque de Fernández García, la novela se desvela como herramienta de conocimiento de la historia y los individuos incluido el escritor- de su tiempo. A partir de esta idea, es posible (re)leer Fortunata y Jacinta atendiendo a todos aquellos detalles a priori irrelevantes para el desarrollo del argumento y la construcción de personajes (los cuales, en muchos casos, precisamente subrayan las contradicciones entre sujeto y sociedad) e investigar y explorar sus contrastes y fracturas.

En «Kundera lector de Broch: la novela como forma de conocimiento», Iris Llop Mangas comprueba el papel del pensamiento de Hermann Broch en la poética de la novela de Milan Kundera. 
Para ello, escoge algunos conceptos clave de la teoría brochtiana, como la concepción epistemológica y polihistórica que define a este género: texto en el que se entretejen diversas cosmovisiones del mundo, de base no racional y normalmente encarnadas en los distintos personajes que, con el avance de las páginas, interrelacionan sus visiones parciales del mundo. Y profundiza en la interpretación que hace de ello Kundera, tanto en el análisis de los textos de Broch como en su propia obra. El autor checo revaloriza el papel de lo acausal y la transformación de la realidad en signos que confunden a los personajes, pero también acomoda o desplaza algunos términos de Broch para conformar una teoría de la novela propia, que pone el foco en lo asistemático, en la falta de dogmatismos y de digresiones filosóficas, con escasas pero luminosas metáforas y tendencia al humor y al ludismo. De una ilusión de totalidad, se llega a un conocimiento interrogativo y de cariz escéptico.

En «Por salvar la poesía épica: usos políticos de la teoría literaria en la Ilustración», Claudia García-Minguillán plantea la continuación del género épico en los siglos XVII y XVIII. En la época ilustrada se cree en la posibilidad de componer una epopeya desde un tiempo distinto a la Antigüedad. Ahora bien, en el contexto de las célebres querellas entre antiguos y modernos, las características del género son discutidas largamente. René Le Bossu, de tono moralista, y G. W. F. Hegel, considerado aquí como continuador de ciertas ideas clasicistas, entienden que la ficción «objetiva» es lo que define a la épica (ni se pierde en inconexiones como hace la historia, ni deja filtrar la voz del poeta como otros géneros literarios). Voltaire apunta al lado opuesto; contrario al afán preceptista propio de su época, escribe la La Henríada alejándose de algunas de las normas de Bossu y fomentando una nueva tendencia literaria gracias a su éxito (Juan Pablo Forner y su canto a Godoy son un ejemplo cercano). Es en este cruce de opiniones y teorías donde la autora del artículo desgaja los principales rasgos de las obras épicas, grecolatinas e ilustradas, centrándose en la figura del héroe y su carácter positivo: a la vez que el modelo estilístico y temático cambia, también cambia el interés gubernamental. Dos paradigmas codependientes, que se retroalimentan al avanzar.

En «Coraje de la verdad y escritura autobiográfica en La muerte del padre de Karl Ove Knausgård», Álvaro Luque Amo retoma la división entre autobiografía (antificción) y autoficción (ficción ambigua) elaborada por Manuel Alberca y analiza, bajo este prisma, las estrategias que Knausgård emplea en el primer tomo de su obra Mi lucha. El concepto foucaultiano de «coraje de la verdad» le es útil a la hora comentar y profundizar en el modo en que el escritor utiliza el tono confesional, la primera persona del singular y el tiempo presente, la intención autoterapéutica o la intertextualidad con uno de los autorretratos de Rembrandt y con En busca del tiempo perdido de Proust. Sin embargo, no habrá que confundir la sinceridad con el relato de hechos verídicos: Knausgård acude a la verdad de su memoria, no a la de la historia. La construcción personal de su identidad biográfica - sea o no cierta en términos referenciales y objetivos- es el cimiento de su identidad narrativa.

En «"Umbrales” de la antología: autoría y género en las poéticas de Ernestina de Champourcin y Josefina de la Torre», Raquel Fernández Menéndez parte de una visión de la antología como artefacto artístico y, entrelazando las teorías surgidas en torno a la figura autorial (escritor imaginario, 
6 Tropelías. Revista de Teoría de la Literatura y Literatura Comparada, número extraordinario 5 (2019) Laro del Río Castañeda

imagen del autor, postura) y las teorías feministas contemporáneas, se plantea el papel de los paratextos de las antologías. Al fin y al cabo, la autorrepresentación, en el caso de las mujeres, puede conllevar una toma de decisiones y la aplicación de estrategias que en cierto sentido subviertan aquellas convenciones históricamente asociadas al género hegemónico. Las breves poéticas y autobiografías de Ernestina de Champourcin y de Josefina de la Torre incluidas en Poesía española. Antología (Contemporáneos), reedición de 1934 del libro de Gerardo Diego, le sirven como objeto de estudio a Fernández Menéndez para ahondar en todas estas ideas. Los textos analizados consiguen amoldarse, ser una más del resto de poéticas y autobiografías escritas por hombres, al mismo tiempo que rechazan una total homogeneización: ni cumplen el estereotipo de escritora, ni aceptan al completo el tradicional rol de escritor.

En «iNo más princesas! Reflexiones de algunas teorías en la enseñanza del amor romántico de la literatura en la vida de los jóvenes actuales desde una perspectiva de género», Juan Pablo Marcoleta Hardessen adopta una posición claramente feminista para leer textos de ámbitos como la Psicología, la Pedagogía y la Sociología. Con ellos reflexiona sobre el papel del imaginario juvenil en torno al amor y la pareja. El repaso de esta bibliografía variada, aliñado con comentarios y críticas a obras culturales de especial incidencia en la formación cultural de las últimas generaciones de nuestra sociedad — de Disney a Netflix—, concluye en una reivindicación enérgica. El énfasis de las exclamaciones del título lo venían avisando: Marcoleta Hardessen expone de forma tajante y explícita su opinión acerca de los paradigmas de género más comunes en el occidente contemporáneo y anima a cambiarlos. La erradicación de los estereotipos romantizados, camino ya iniciado por algunos textos literarios y audiovisuales de los últimos años, le resulta imprescindible.

En «La literatura como afirmación de una existencia: Cómo leer cuando las personas trans se escriben», Eric Sancho Bru pone de relieve un lenguaje y un género literario surgidos desde la subalternidad del sistema binomial de sexo-género que domina en nuestra época. La mayoría del vocabulario y la mitología trans, hasta fechas recientes, proviene de la medicina, un ámbito del saber que ha tachado de anormal, es decir, de enfermizo y patológico, la diversidad de género. Ante esto, una respuesta común por parte de lxs autorxs trans ha sido la escritura del yo: la literatura como espacio donde llegar a ser y la literatura como vehículo comunicativo para difundir subjetividades alejadas de lo hegemónico. Sancho Bru se adentra así en los nuevos códigos de tres libros contemporáneos escritos en español por personas trans, Transito (2015) de Ian Bermúdez, El despiste de Dios (2016) de Diego Neria y El bebé verde (2016) de Roberta Marrero. La fuerza de la primera persona del singular, la intención poética manifiesta en el estilo, la fundación de nuevos modelos de sujeto y de autoría, la falta de dogmatismos y esquemas prefijados... son algunos de los rasgos que parecen formar este género todavía en crecimiento.

En «La teoría de la literatura como metodología de estudio del paisaje cultural», María Isabel Morales Sánchez reivindica la necesidad de unir lazos entre los estudios de la literatura y de otras disciplinas artísticas. El paisaje cultural, objeto de análisis habitual en arquitectura, geografía, economía, pintura o gestión cultural, guarda una relación de doble dirección con la tradición literaria: 
el uno influye en la otra y viceversa. Y es que los paisajes y sus representaciones, al mezclar lo natural y lo cultural, fomentan la reflexión sobre las relaciones entre el individuo y el medio que habita. Entender, desde la literatura y los estudios literarios, su historia y su construcción discursiva se hace posible mediante las herramientas que nos ofrece la Semiótica de la Cultura de Lotman y la Retórica Cultural de Albaladejo; y mantener un diálogo abierto con los Estudios Culturales, señala la autora, permitirá dibujar en toda su complejidad los aspectos semióticos de la comunicación, también en el análisis paisajístico. El artículo de Morales Sánchez termina enumerando posibilidades de estudio, algunas con mayor trayectoria que otras en la investigación de las últimas décadas, desde la poética de las ruinas al papel del turismo, pasando por los discursos de identidad nacional o local y las nuevas textualidades que hibridan lo tradicional y lo digital.

En «Agencialidades, mediaciones y autoridades: claves para leer el campo literario hoy», Cristina Martínez Tejero expone algunas de las principales relaciones que se establecen entre el modelo económico neoliberal y la cultura actual. A la concentración de empresas del sector editorial y la aparición de profesiones especializadas en este mercado (agencias, talleres...) hay que sumar el surgimiento de toda una serie de iniciativas materialistas y ultratextuales características de nuestro tiempo: las ciudades y villas literarias, los festivales literarios, el turismo literario... Las posibilidades y contrapartidas asociadas a la tecnología, desde la disociación territorial a la ruptura de los roles clásicos de productor y consumidor, pasando por el aislamiento ideológico ligado a la comunicación dirigida, dibujan un escenario en el que la publicidad de la figura del autor se vuelve indispensable y en el que los criterios se globalizan y regularizan mediante los sistemas de puntuaciones, los me-gustas y las valoraciones (impresionistas, por lo general) de los booktubers y otros celebrities. Martínez Tejero delinea así estas nuevas estructuras del campo literario, profundamente dependientes de las lógicas económicas, que forman un nuevo contexto rico y sugerente para la teoría literaria y la literatura comparada.

\section{Bibliografía}

Althusser, L. (1970). Sobre el trabajo teórico: dificultades y recursos. Barcelona: Anagrama.

De Certeau, M. (1996). La invención de lo cotidiano. 1. Artes de hacer. México D. F.: Universidad Iberoamericana.

Derrida, J. (2010). La hospitalidad [con un texto de A. Dufourmantelle intercalado]. Buenos Aires: Ediciones de la Flor.

Fokkema, D. W. (1989). «La literatura comparada i el nou paradigma», Els Marges, 40, 5-18.

Foucault, M. (1970). La arqueología del saber. México: Siglo XXI.

Núñez Ramos, R. Á. (2017). «La literatura como experiencia. Entre Aristóteles y la neuroestética», Tropelías, número extraordinario 1, 221-235.

Sánchez-Mesa Martínez, D. (2015). «Los estudios sobre la cibercultura y los new media. Extendiendo el campo de la literatura comparada», Caracteres, 4(2), 79-99. 
8 Tropelías. Revista de Teoría de la Literatura y Literatura Comparada, número extraordinario 5 (2019) Laro del Río Castañeda

Saussy, H. (2006). Comparative Literature in an Age of Globalization. Nueva York: The Johns Hopkins University Press.

Todorov, T. (1978). "Presentación". En T. Todorov (Comp.), Teoría de la literatura de los formalistas rusos por Jakobson, Tinianov, Eichenbaum, Brik, Shklovski, Vinogradov, Tomashevski, Propp. México: Siglo XXI (3. a edición), 11-20.

— (2009). La literatura en peligro. Barcelona: Galaxia Gutenberg.

Watson, W. (2008). La arquitectónica del significado. Fundamentos del nuevo pluralismo. Córdoba: Berenice.

Wittgenstein, L. (2009). Investigaciones filosóficas [con Tractatus lógico-philosophicus y Sobre la certeza]. Madrid: Gredos. 